\section{Extinction of operant responses by rats under the effects of Cannabis sativa extract}

\author{
SERGIO C. GONZÁLEZ* and E. A. CARLINI \\ Setor de Psicofarmacologia \\ Departmento de Bioquimica e Farmacologia, Escola Paulista de Medicina \\ Rua Botucatu, 862, São Paulo, Brasil
}

Rats previously trained in T-and Lashley III mazes and injected with cannabis extract during extinction showed an equal trend to extinguish when compared to control animals. On the other hand, rats which had been trained in the T-maze under marihuana action extinguished as controls when extinction sessions were carried out without drugs. These data speak against the hypothesis, put forth to explain the effects of cannabis in reducing CER of rats, that marihuana compounds potentiate dominant responses.

Reports have been published dealing with the effects of marihuana compounds on conditioned emotional responses (CER) of rats. Boyd et al ( 1963 ) o bserved that dimethylheptyltetrahydrocannabinol accentuates the conditioned suppression of barpressing behavior, attributing such an effect to the general depression induced by the drug. Opposite results were obtained by Abel (1969) and Gonzalez et al (1970), who observed that pyrahexyl and cannabis extract, respectively, partially blocked the suppressive effects of a CS previously paired to a US in a CER situation. They suggested that the drugs reduced emotional fear, thus facilitating the emission of the ongoing behavior. On the other hand, Walters \& Abel (1970) proposed an alternative hypothesis that the drug would potentiate the dominant response of the animals' repertoire, yielding the same final result. This, however, does not explain the results obtained by Gonzalez et al (1970), who observed a decrease in defecation of drugged rats in the CER situation. These findings speak favorably to the fear reduction hypothesis, because defecation has been considered a reliable index of emotionality in rats (Henderson, 1970). The present experiments were undertaken to further analyze this point. It was reasoned that if cannabis facilitated the emission of a dominant response, then the extinction of an operant response by drugged animals would take longer to occur.

\section{SUBJECTS AND DRUGS}

The Ss were 40 male and 40 female Wistar rats, 3 months old at the beginning of the experiment. An extract of flowering tops of Cannabis sativa (marihuana) and a control solution were prepared and used according to Carlini \& Kramer (1965).

*This research was conducted under a fellowship from Fundaça de Amparo à Pesquisá do Estado de São Paulo (FAPESP).
Previous assays on rabbits (Gayer test) performed as described by Santos et al (1966), have shown that the extract abolished the corneal reflex at a dose of $0.34 \pm 0.19 \mathrm{mg} / \mathrm{kg}$ (average $\pm \mathrm{SD}$ ); this indicates that the extract contained approximately $29 \%$ of (-) $\Delta^{9}$-trans-tetrah ydrocannabinol (Carlini et al, 1970b).

\section{PROCEDURE}

T-Maze

Five groups (I to $\mathrm{V}$ ) of 10 rats each balanced for sex and weight, were used. The animals, starved $22 \mathrm{~h}$, were trained twice every second day to turn right in the apparatus in order to receive $30 \mathrm{sec}$ food reward; the longer arm of the maze (starting point) measured $80 \mathrm{~cm}$ and the shorter ones, $40 \mathrm{~cm}$. Groups I and II received, beginning from the first experimental session, respectively, $10 \mathrm{mg} / \mathrm{kg}$ of the extract and $1.0 \mathrm{ml} / \mathrm{kg}$ of the control solution through intraperitoneal route (IP) $45 \mathrm{~min}$ before each session. After reaching a learning criterion of three consecutive sessions without errors, the extinction sessions started; no drugs were administered during this phase. Groups III and IV were trained without drugs; extinction sessions, however, were carried out under $10 \mathrm{mg} / \mathrm{kg}$ of marihuana (III) and $1.0 \mathrm{ml} / \mathrm{kg}$ of control solution (IV). Group V received the same amount of marihuana, but food reward was maintained during the "extinction" phase.
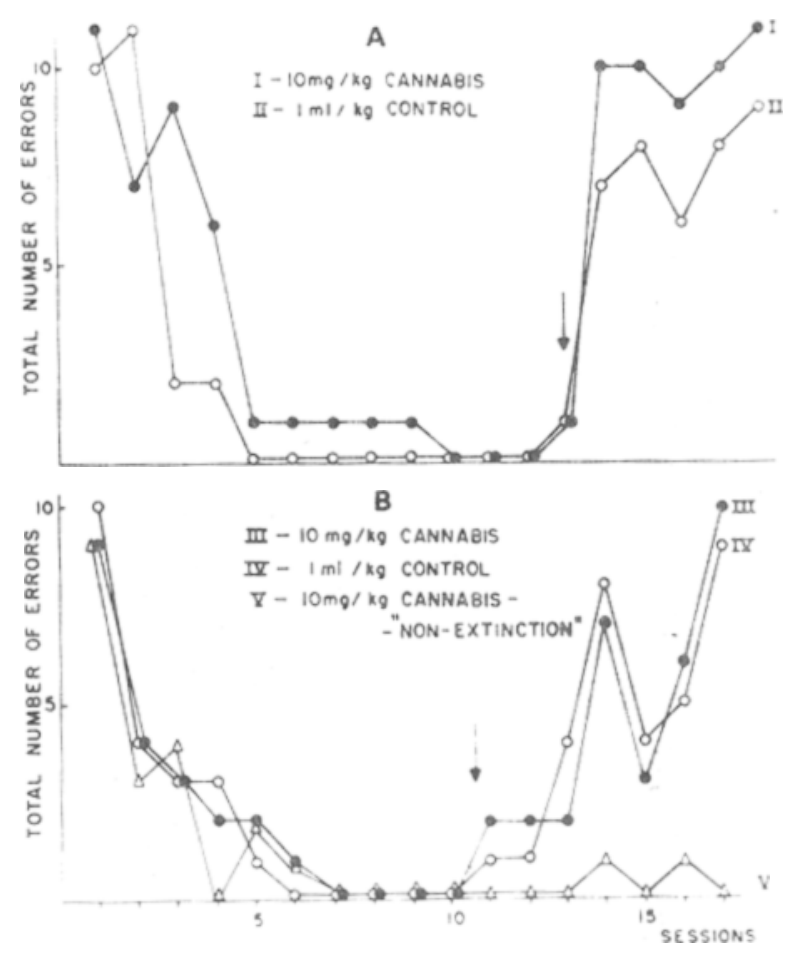

Fig. 1. Effects of $10 \mathrm{mg} / \mathrm{kg}$ of Cannabis sativa extract $(\bullet)$ and $1.0 \mathrm{ml} / \mathrm{kg}$ of control solution $(0)$ on learning and extinction of rats in a T-maze. (A) The drugs were administered during the learning phase (turning right) and extinction was carried out without drug administration. (B) No drug was applied during the learning phase and extinction was carried out under drug action. The arrows indicate the beginning of extinction sessions with no food reward for Groups I-IV. $(\Delta)$ Rats injected with $10 \mathrm{mg} / \mathrm{kg}$ of cannabis extract but with food reward maintained during "extinction" phase. The ordinates represent the total number of errors (turning left) for each group of 10 rats. 


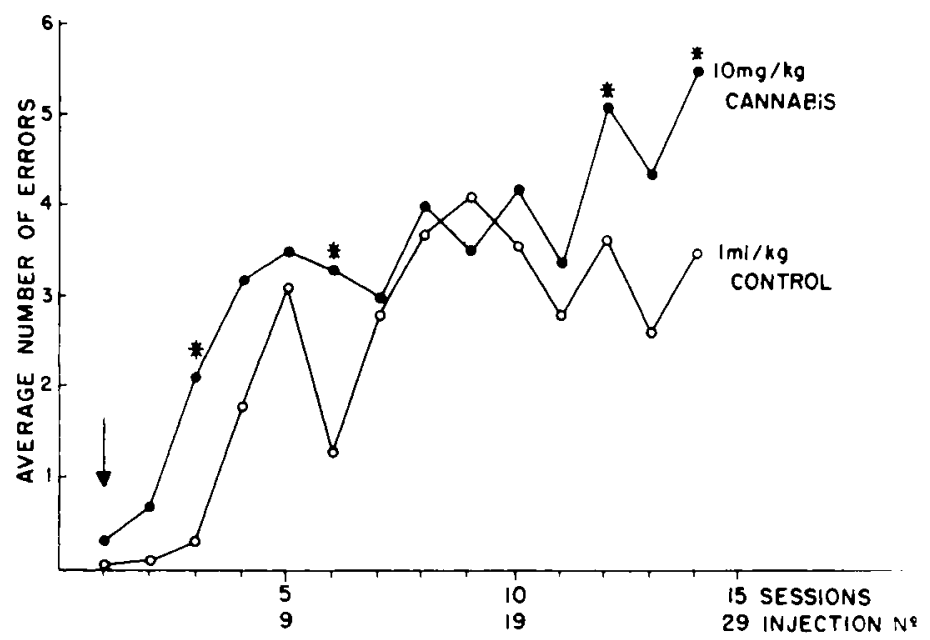

Fig. 2. Effects of Cannabis sativa extract on extinction of rats in a Lashley III maze. (•) Rats injected with $10 \mathrm{mg} / \mathrm{kg}$ of canabis extract; (0) control animals injected with $1.0 \mathrm{ml} / \mathrm{kg}$ of control solution. The asterisks indicate significant differences from controls ( $p \leqslant .05 ;$ Mann-Whitney $U$ test).

Lashley III Maze

Two groups of 15 rats each, starved $22 \mathrm{~h}$, were trained once every other day in the apparatus according to the procedure described by Carlini \& Kramer (1965). After reaching three sessions without errors, the extinction sessions were started; during this phase, one of the groups was injected daily with $10 \mathrm{mg} / \mathrm{kg}$ of extract and the other with a control solution. Extinction sessions were performed every $48 \mathrm{~h}$.

RESULTS AND DISCUSSION

The data from the $T$-maze show that extinction of the dominant response of the rats' repertoire (turning right) was not affected by marihuana, either when the task was learned under drug action (Fig. 1; Part A; Group I) or when extinction sessions were carried out with drugged animals (Fig., 1; Part B; Group III). It could be said that the operant obtained in a $\mathrm{T}$-maze is rather a simple one and, therefore, not accessible to the marihuana effects. Experiments performed in the more elaborate
Lashley III maze demonstrated that this was not the case; as can be seen in Fig. 2, marihuana was not able to potentiate the dominant response of rats, i.e., it did not delay the extinction. The significant decay of performance observed in Sessions 3 and 6 (Fig. 2) was probably due to the capacity of marihuana compounds to interfere with performance capabilities of rats (Carlini et al, 1970a); however, as tolerance to marihuana developed (Carlini, 1968; Silva et al, 1968), control and cannabis-treated rats showed an equal trend to extinguish (Fig. 2; 7th to 12th session; 13th to 21st injection). Furthermore, as seen in Fig. 2 (last three sessions), a facilitating effect of marihuana on extinction was noted.

In conclusion, the present data do not support the hypothesis of Walters and Abel (1970) that marihuana potentiates the dominant response of rats's repertoire. Therefore, we do not feel that it is the best explanation to account for the effects of these compounds in partially blocking the CER of rats.

\section{REFERENCES}

ABEL, $E$. $L$ Effects of the marihuana homologue, pyrahexyl, on a conditioned emotional response. Psychonomic Science, $1969,16,44$

BOYD, E. S., HUTCHINSON, E. D., GARDNER, L. C. \& MERITT, D. A. Effects of tetrahydrocannabinols and other drugs on operant behavior in rats. Archives Internationales de Pharmacodynamie et de Therapie, 1963 . $144,533-554$.

CARLINI, E. A. Tolerance to chronic administration of Cannabis sativa (marihuana). Pharmacology, 1968, 1. 135-142.

CARLINI, E. A., HAMOUI, A., BIENIEK, D. \& KORTE, F, Effects of (-) $\Delta^{9}$-trans-tetrahydrocannabinol and a synthetic derivative on maze performance of rats. Pharmacology, 1970a, 4, 359-368. 359-368.

CARLINI,E. A., \& KRAMER, C. Effects of Cannabis sativa (marihuana) on maze performance of the rat. Psychopharmacologia (Berlin), 1965, 7 175-181.

CARLINI, E. A.. SANTOS, M.. CLAUSSEN, U.. BIENIEK, D.. \& KORTE, F. Structure activity relationship of four tetrahydrocannabinols, and pharmacological activity of five semipurified extracts of Cannabis sativa. Phsychopharmacologia (Berlin), $1970 \mathrm{~b}, 18,82-93$

GONZALEZ, S. C., KARNIOL, I. G., \& CARLINI, E. A. Effects of Cannabis sativa extract on conditioned fear. Read before the XXII annual meeting of Brazilian Society for Advancement of Science (SBPC), July 1970.

HENDERSON, N. D. Behavioral reactions of Wistar rats to conditioned fear stimuli, novelty and noxious stimulation. The Joumal of Psychology, 1970, 75, 19-34.

SANTOS, M.. SAMPAIO, M. R. P.. FERNANDES, N. S., \& CARLINI, E. A. Effects of Cannabis sativa (marihuana) on the fighting behavior of mice. Psychopharmacologia (Berlin), 1966,8, 437-444.

SILVA, M. T. A., CARLINI, E. A., CLAUSSEN, U., \& KORTE, F. Lack of cross-tolerance in rats among (-) $\Delta^{9}$-trans-tetrah y drocannabinol. cannabis extract, mescaline and lysergic acid diethylamide (LSD-25). Psychopharmacologia (Berlin), 1968, 13 , 332-340.

WALTERS, G, C., \& ABEL, E. L. Effects of a marihuana homologue (Pyrahexyl) on avoidance learning in the gerbil. Journa of Pharmacy \& Pharmacology, 1970, 22, 310-312. 